\title{
Understanding Behaviour Patterns of Multi-Agents in Digital Business Ecosystems: An Organisational Semiotics Inspired Framework
}

\author{
Prince Kwame Senyo ${ }^{1,2}$, Kecheng Liu ${ }^{1,3}$, John Effah $^{2}$, \\ ${ }^{1}$ Informatics Research Centre, Henley Business School, University of Reading, Reading, United \\ Kingdom \\ 2 Department of Operations and Management Information Systems, University of Ghana Business \\ School, Accra, Ghana \\ ${ }^{3}$ Wuhan College, Wuhan, China \\ pksenyo@ug.edu.gh, k.liu@henley.ac.uk, jeffah@ug.edu.gh
}

\begin{abstract}
Digital business ecosystem (DBE) is a collaborative network of organisations, processes and technologies that collectively create value. Thus, value creation in digital business ecosystems is jointly undertaken by multiple human and digital agents. To aid appropriate apportionment of work and design of information systems, it is essential to understand behaviour of both human and digital agents. However limited attention has been paid to agents' behaviour in the extant digital business ecosystems literature. Moreover, multi-agent research has also largely focused on technical issues while limited research exists on agents' behaviour. As such, in this paper, we develop a framework to understand behaviour patterns of multi-agent in DBEs. This framework builds its foundation on the theoretical lens of Organisational Semiotics, a sociotechnical theory towards contribution to DBE research.
\end{abstract}

Keywords: Behaviour Analysis Framework · Multi-Agent Behaviour · Digital Business Ecosystem (DBE) · Organisational Semiotics · Social and Digital Agents

\section{$1 \quad$ Introduction}

Digital business ecosystem (DBE) refers to a sociotechnical collaborative environment of different organisations supported by information and communication technologies (ICTs) to collectively create value $[12,13]$. In DBEs, two main entities-people within organisations and digital artefacts, are the actors responsible for value creation. As such, DBEs can be viewed as a multi-agent environment constituted by social and digital agents. An agent refers to an entity capable of carrying out some behaviour to produce some effect. For instance, an organisation responsible for supplying inputs in a DBE is an agent due to the role it performs. Similarly, a digital platform for processing transactions within the DBE is also an agent due to its facilitation of operations.

Agent behaviour refers to any course of action undertaken by an entity during execution of activities [8]. These behaviours include seeking for resources, producing 
goods and services, as well as communicating with others. Additionally, agent behaviours occur in different forms, levels, modes and among different entities. As such, understanding these behaviours is vital but difficult in multi-agent environments. Within DBEs, agent behaviours occur in a sociotechnical nature due to the presence of both social and digital agents. Social agents refer to individuals, department and organisations that undertake certain behaviours in DBEs [6]. On the other hand, digital agents are technologies that usually undertake delegated duties based on pre-defined rules on behalf of social agents [2]. Digital agents perform computer mediated activities that are repetitive and mostly do not require high level discretional decisions. The performance of activities by the social and digital agents is what result in different behaviours.

In the extant DBE research, limited attention has been paid to multi-agent behaviour. We argue that understanding multi-agent behaviour is important to: 1) accurately apportion work among agents according to their capabilities, 2) support design and development of appropriate information system for DBEs, and 3) promote operational efficiency. Based on the knowledge gap in the extant literature and the crucial importance of understanding multi-agent behaviour, in this study, we postulate the research question: what behaviours do multi-agents exhibit in digital business ecosystems? To address this research question, this study develops a multi-agent behaviour analysis framework through the lens of organisational semiotic theory.

The rest of the paper is organised as follows. Section 2 presents literature review on DBE and multi-agents. Section 3 discusses the theoretical foundation of organisational semiotics. Section 4 presents our proposed framework while Section 5 demonstrates its application through a case study of Ghana's port DBE. Finally, Section 6 presents discussions and conclusion.

\section{$2 \quad$ Literature Review}

\subsection{Digital Business Ecosystems}

As business environments experience increasing sophistication in customer preferences, in response, organisations are forming alliances to adequately address these needs. These alliances have led to new collaborative networks referred to as DBEs. DBE is a digitally enabled collaborative network of individuals, organisations, and technologies that collectively create value [12,13]. DBE offers an innovative way for organisations to collectively create value that is usually beyond their individual capabilities. DBE is made up of two main dimensions: digital ecosystem and business ecosystem [12]. Digital ecosystem refers to a virtual environment populated by digital species such as software, applications, hardware, and processes analogous to organisms in the biological ecosystem [3]. Digital ecosystems operate as a peer-to-peer distribution technology infrastructure that creates, disseminates, and connects digital services over the internet.

On the other hand, business ecosystem refers to an economic community of individuals and organisations operating outside their traditionally define industry boundaries to collectively create value for customers who themselves are participants in the ecosystem [11]. Drawing from the two main concepts, we can argue that DBEs 
are multi-agent environments made up of two agent classes- social and digital agents. The social agents are individuals and organisations that undertake operations in the business ecosystem aspect of DBEs. In contrast, digital agents refer to technical components within the digital ecosystem aspect of DBEs that perform delegated tasks from social agents. Thus, for service delivery in DBEs, there is a need for coherent interaction between social and digital agents.

While the extant DBE literature provides interesting insights, there is still a paucity of research on other fundamental aspects such as multi-agent behaviour. Drawing from the trend in the extant DBE literature, there is a dearth of knowledge on the behaviour analysis of multi-agents. Given that comprehensive understanding of multi-agent behaviour will lead to better analysis, design and alignment of DBE information systems, it is therefore important to understand how this phenomenon occurs. Thus, the task going forward is how to comprehensively analyse the behaviour of both digital and social agents within DBEs. To fill this gap, this study develops a multi-agent behaviour analysis framework for DBEs.

\subsection{Multi-Agents}

Multi-agent is a well-grounded concept that describes a composition of multiple interacting entities. While some studies [e.g., 2, 5, 14] view agents as computer software that act either for an agency relationship or autonomously to achieve some objectives, in reality, an agent is more than just a computer software. An agent could be a person, an organisation, device, or a computer software that performs a task. In this vein, we argue that the term multi-agent is a characterisation of two agent classes- social and digital. Social agents represent actors such as people, departments and organisations [6] while digital agents signify computer enabled actors such as devices and software [2]. Thus, for agents to successfully interact and pursue their respective objectives, there is a need for cooperation, coordination and negotiation among agents.

While multi-agent research has witnessed many studies over the years, much focus has been on digital agents. Largely, these studies focus more on digital agent modelling $[1,2,6]$, and simulation [5] within multi-agent systems while limited understanding exists on the underlying behaviour of both social and digital agents. Although the contributions from the extant multi-agent studies are vital, we believe the outcomes of these studies would have significantly improved if better understanding exist on behaviour pattern of both social and digital agents. As such, there is a vital need to understand the behaviour of multi-agents.

\section{Theoretical Foundation}

Organisational semiotics is a branch of Semiotics that investigates the use of signs in organisations. A sign is something that stands to someone or a community for something in a particular setting [9]. In this study, organisational semiotics is used as the theoretical foundation for our proposed behaviour analysis framework because (1) it is firmly grounded in agents and behaviour investigation [9], and (2) it supports the sociotechnical nature of DBEs by accommodating both social and technical perspectives [10]. For this study, we adapt the norm analysis and organisational 
morphology methods of organisational semiotics theory for our investigation. These methods are chosen because they prescribe actions that foster better understanding of behaviours. Also, these methods accommodate both social and digital agents present in DBEs.

Norm analysis is a method that delineates triggers, events and constraints to capture dynamics within a domain. Norms refer to dynamic conditions that underlie behavioural patterns and dictate how members behave, think, make decisions, and perceive the world [9]. Thus, norms include formal and informal rules, regulations, and laws. The norm specification format is as follows:

whenever <context $>$ if <condition $>$ then <agent $>$ is <deontic operator $>$ to $\langle$ action $>$

Organisational morphology studies behaviours using three norms - substantive, communication and control [9]. Substantive norms direct core business functions. For instance, substantive norms can direct how customer orders are processed. Communication norms govern activities involving message passing between agents. For instance, communication norms are responsible for directing how an application confirmation email is sent from a system to an applicant. Control norms regulate substantive and communication norms through sanctions and rewards. For instance, control norm is responsible for denying access if a user provides invalid credentials in logging into a system.

\section{Behaviour Analysis Framework}

In this section, we address the research question: what behaviours multi-agents exhibit in digital business ecosystems by presenting our proposed framework. The framework as presented in Figure 1 has three iterative stages to identify, analyse, and understand the behaviour of multi-agents in DBEs. Each stage of the framework shows components, techniques, and outcomes as discussed below. 


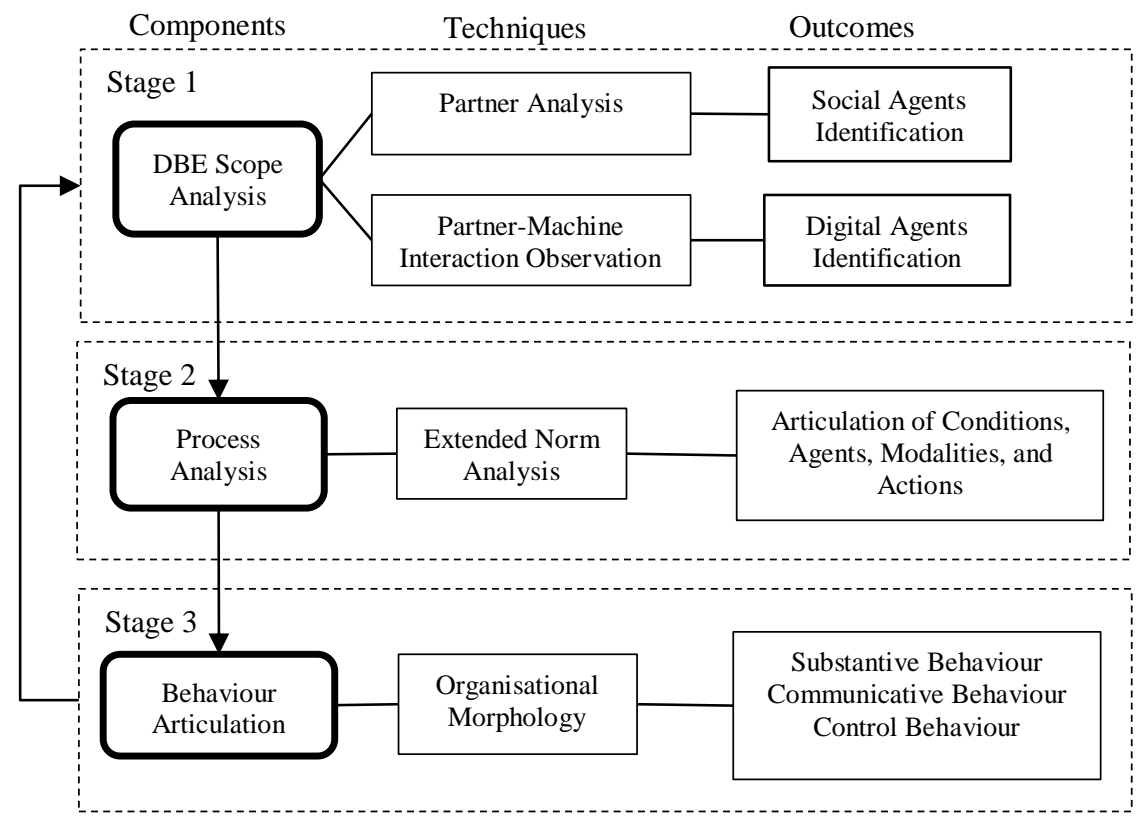

Fig. 1 Multi-agent Behaviour Analysis Framework in DBEs

Stage 1. This stage focuses on establishing the context in which multi-agent behaviours occur. The techniques supporting this stage are the partner analysis and the partner-machine interaction observation. First, the partner analysis technique provides a systematic approach to elicit social agents as well as determine their role and responsibilities to understand the DBE partnership, scope, and behaviour. We define a $D B E$ partner as an individual or organisation that contributes direct inputs into core DBE processes or exchanges resources with another partner. Partner identification in DBEs is a challenging task. In fact, Iansiti and Levien [4] allude that it is impossible to articulate all partners of an ecosystem. Thus, they suggest that in partner identification, consideration should be given to partners with whom the future of a DBE intertwines.

Based, on our definition of a DBE partner, we proposed an identification procedure in Figure 2. Drawing on the stakeholder analysis approach from the organisational semiotics theory [7], we categorise DBE partners. The categorisation determines the roles, responsibilities and influence a partner has in a DBE. Partner role refers to the capacity to perform some functions. Similarly, partner responsibility refers to the obligation accorded a role to perform functions. Partner influence represents the impact the partner has on a DBE and vice versa. The partner analysis technique arranges the roles chronologically based on their influence in the DBE. As such, the closer the partner category to the DBE, the more influential the partner. Based on our definition of DBE partner, we outline four categories and associated roles namely, actor, client, facilitator and regulator.

$$
\text { Role }=\text { Actor } \mid \text { Client } \mid \text { Provider } \mid \text { Regulator }
$$


Actor represents a key partner that contributes to core processes within the DBE. Client is the beneficiary of DBE efforts. On the other hand, provider offers resources and conducive environment for the smooth running of a DBE. Regulator refers to an organisation that provides guidelines that controls the behaviour of other partners in a DBE. Thus, partner roles and responsibility in DBEs can be formalised as: DBE \{partner, roles and responsibility\}. Figure 2 shows partner roles and their level of influence in a DBE. It is worth noting that partners may perform multiple roles with varied responsibilities. Given that partner identification and analysis, especially in DBEs, is very difficult we consider our approach a significant contribution to DBE research.

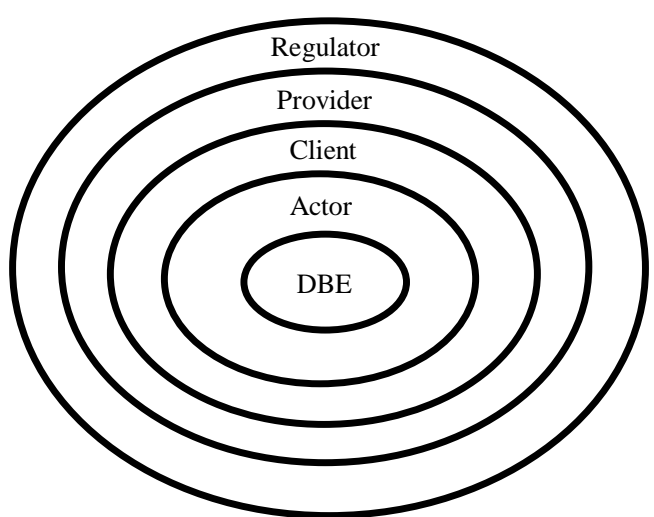

Fig 2 Partner roles (adapted from [7])

Second, the partner-machine interaction observation technique focuses on how partners use digital agents within a DBE. The aim of this technique is to delineate the behaviour of digital agents by observing how they interact with others as well as partners. This technique is carried out by observing and taking comprehensive notes of how partners interact with digital agents. Also, partners are asked for additional information regarding the operation, purpose, and meaning of their interactions with digital agents. Thus, by observing the interaction between these agents, we can derive their behaviours to support information system analysis, development and alignment.

Stage 2. This stage takes a process perspective by analysing the sequence of interactions between social and digital agents to understand interactions towards articulation of conditions, agents, modalities and actions that cause behaviours. We extend the original norm specification to include process, predecessor, and successor components to aid the multi-agent behaviour analysis. As a result, the extended norm specification is:

$<$ Process ID $>\langle$ Process $><$ Predecessor $>$ Behaviour specification \{whenever

$<$ Context $\rangle$ if $\langle$ Condition $\rangle$ then $\langle$ Agent $\rangle$ is $\langle$ Deontic Operator $\rangle$ to $\langle$ Action $\rangle\}$ <Successor $>$ 
The process ID is an identification for process. The process element details the series of actions to achieve a goal. The predecessor element determines triggers for processes while the successor refers to the next activity to be undertaken when all predecessor conditions are met. The context represents the environment in which an agent occupying a role can perform an action. The condition component refers to constraints that must be met for an agent to perform an activity. The agent component designates a partner or digital agent who performs an activity. On the other hand, deontic operator denotes the expressiveness of norms by establishing whether an agent is permitted or obliged to take an action in relation to a process. Lastly, the action refers to a process an agent performs because of a triggered predecessor.

Stage 3. This last stage utilises the result from stages 1 and 2 to derive the behaviour of multi-agent in DBEs. This stage involves analysis and classification of processes undertaken by agents to delineate their behaviours. We define three main behaviours, namely substantive, communication, and control [13] for interactions between multiagents. Even though we proposed three main behaviour classifications, there could be further expansion. As a result, substantive actions may include communication and control behaviours. Similarly, communication actions may also include substantive and control behaviours. Lastly, control actions may also include substantive and communication behaviours.

\section{Case Study Application}

To demonstrate application of our framework in understanding multi-agent behaviours in DBEs, we conducted a case study in the vehicle clearing domain at Ghana's main harbour, Tema Port. We chose Ghana's port because it provides an empirical instantiation of a DBE. Ghana is a middle-income Sub-Saharan African country. One of the main sources of revenue for the Government is import duties. As such, significant investment has been made to streamline processes at the ports of entry to generate more revenue. In this study, a high-level view of the vehicle clearing process are as follows: 1) Importer uses an electronic ministry department and agency (e-MDA) platform to obtain a unique consignment reference (UCR), 2) Importer uses the e-MDA platform to submit import declaration form (IDF), 3) Importer uses the Pre-Arrival Assessment Reporting System (PAARS) to apply for Customs Classification and Valuation Report (CCVR), 4) Customs valuation officers use the PAARS to process application for CCVR, 5) Importer uses the Ghana Customs Management Systems (GCMS) to submit customs declaration, 6) Customs compliance officers process declaration using the GCMS to determine import duty, 7) Importer relies on banks to make duty and other charges payment, 8) Importer uses the Ghana Integrated Cargo Clearance System (GICCS) to submit request for shipping release, 9) Customs examination officers use GCMS to release vehicle after physical examination, and 10) Importer relies on the Driver and Vehicle Licensing Authority (DVLA) for temporary number plate.

Stage 1: DBE scope analysis: From our framework (see Figure 1), we perform partner analysis and partner-machine interaction observation to articulate social and digital agents in the import DBE. As established earlier, partners such as individual and organisations in DBEs are analogous to social agents. From the analysis, we identified five key partners as social agents in the vehicle clearing domain of Ghana's port DBE. 
These social agents are importers, Customs, shipping lines, banks, and DVLA. Table 1 presents the social agents, their category, and responsibilities in the import DBE.

Table 1. Ghana's port DBE social agents and responsibility

\begin{tabular}{|c|c|c|}
\hline $\begin{array}{c}\text { Partners } \\
\text { (Social Agents) }\end{array}$ & Category & Responsibility \\
\hline Importers & Client & Submitting vehicle clearing application and paying appropriate duty \\
\hline Customs & Actor & $\begin{array}{l}\text { Performing vehicle clearing application valuation, compliance } \\
\text { processes and physical examination }\end{array}$ \\
\hline Shipping lines & Actor & Processing shipping release request \\
\hline Banks & Actor & Receipts of duty payments and sending payment notification to Customs \\
\hline DVLA & & Provision of temporary vehicle number plate to importers \\
\hline
\end{tabular}

The partner-machine interaction observation articulates digital agents through scrutiny of their interaction with social agents. This step is mainly achieved by observing the interaction between social agents as they carry out work. From the case study, we identified five major digital agents, namely e-MDA, PAARS, GCMS, banking systems and GICCS. Table 3 shows the digital agents articulated and their responsibilities.

Table 2. Ghana's port DBE digital agents and responsibility

\begin{tabular}{ll}
\hline Digital Agents & Responsibility \\
\hline e-MDA & For generating UCR and processing of IDF \\
PAARS & For processing CCVR \\
GCMS & For declaration processing, receipts of payment notification and release of vehicles \\
Banking systems & For processing and notification of Customs of duty payment \\
GICCS & For processing shipping release requests \\
\hline
\end{tabular}

Stage 2: Process Analysis. This stage focuses on establishing conditions, agents, modalities and actions underpinning processes. We utilised the extended norm analysis technique to understand the underlining rules, conditions, agents and triggers in a particular process to articulate multi-agent behaviour. Table 3 presents the extended norm analysis based on the processes identified from our case study. From the case study, 10 processes were identified and assigned identifications P1 to P10. Similarly, the predecessors identified from the case study are triggers for each process. The behaviour specification aspect of the extended norm analysis technique entails the context, condition, agents, and deontic operator elements related to processes. Lastly, the successor element presents processes that will be triggered because of a successful execution of a current process. 
Table 3. Behaviour specification of vehicle clearing processes in Ghana's port DBE

\begin{tabular}{|c|c|c|c|c|}
\hline ID & Process & Predecessor & Behaviour Specification & Successor \\
\hline $\mathrm{P} 1$ & Obtaining UCR & $\begin{array}{l}\text { <vehicle is } \\
\text { imported > }\end{array}$ & $\begin{array}{l}\text { WHENEVER < a vehicle is imported }> \\
\text { IF <importer is ready to clear the vehicle> } \\
\text { THEN <importer> IS < permitted > to obtain } \\
\text { UCR through the e-MDA platform }\end{array}$ & Submission of IDF \\
\hline P2 & Submitting IDF & $\begin{array}{l}\text { Obtaining } \\
\text { UCR }\end{array}$ & $\begin{array}{l}\text { WHENEVER <importer generates a UCR> IF } \\
\text { <all required documentation are provided> } \\
\text { THEN <importer> IS < permitted > to submit } \\
\text { IDF through PAARS }\end{array}$ & $\begin{array}{l}\text { Submitting CCVR } \\
\text { application }\end{array}$ \\
\hline P3 & $\begin{array}{l}\text { Submitting } \\
\text { CCVR } \\
\text { application }\end{array}$ & $\begin{array}{l}\text { Submitting } \\
\text { IDF }\end{array}$ & $\begin{array}{l}\text { WHENEVER < importer submits IDF> IF < all } \\
\text { required documentation are provided }>\text { THEN } \\
\text { <importer }>\text { IS < <ermitted }>\text { to submit CCVR } \\
\text { application through PAARS }\end{array}$ & $\begin{array}{l}\text { Processing CCVR } \\
\text { application }\end{array}$ \\
\hline P4 & $\begin{array}{l}\text { Processing } \\
\text { CCVR } \\
\text { application }\end{array}$ & $\begin{array}{l}\text { Submitting } \\
\text { CCVR } \\
\text { application }\end{array}$ & $\begin{array}{l}\text { WHENEVER < importer submits CCVR } \\
\text { application }>\text { IF }<\text { all required documentation } \\
\text { are provided }>\text { THEN < Customs }>\text { IS < obliged }> \\
\text { to process CCVR application through PAARS }\end{array}$ & $\begin{array}{l}\text { Declaration } \\
\text { submission }\end{array}$ \\
\hline P5 & $\begin{array}{l}\text { Declaration } \\
\text { submission }\end{array}$ & $\begin{array}{l}\text { Processing } \\
\text { CCVR } \\
\text { application }\end{array}$ & $\begin{array}{l}\text { WHENEVER < Customs processes CCVR } \\
\text { applications> IF < all requirements are met> } \\
\text { THEN <importer> IS < permitted > to submit } \\
\text { declaration application through GCMS }\end{array}$ & $\begin{array}{l}\text { Compliance \& duty } \\
\text { determination }\end{array}$ \\
\hline P6 & $\begin{array}{l}\text { Compliance \& } \\
\text { duty } \\
\text { determination }\end{array}$ & $\begin{array}{l}\text { Declaration } \\
\text { submission }\end{array}$ & $\begin{array}{l}\text { WHENEVER < importer submits declaration } \\
\text { application> IF < all required documentation are } \\
\text { provided > THEN < Customs> IS < obliged> to } \\
\text { perform compliance processes and determine } \\
\text { duty to be paid through GCMS }\end{array}$ & Duty payment \\
\hline P7 & Duty payment & $\begin{array}{l}\text { Compliance \& } \\
\text { duty } \\
\text { determination }\end{array}$ & $\begin{array}{l}\text { WHENEVER < Customs performs compliance } \\
\text { processes and determines duty to be paid }>\text { IF } \\
<\text { importer pays the right amounts }>\text { THEN } \\
<\text { bank }>\text { IS < obliged }>\text { to process duty payment } \\
\text { and notify Customs of the transaction }\end{array}$ & $\begin{array}{l}\text { Shipping release } \\
\text { request }\end{array}$ \\
\hline P8 & $\begin{array}{l}\text { Shipping release } \\
\text { request }\end{array}$ & Duty payment & $\begin{array}{l}\text { WHENEVER <importer pays import duty> IF } \\
\text { < all charges are paid> THEN <importer> IS } \\
\text { <permitted> to make shipping release request } \\
\text { through the GICCS }\end{array}$ & $\begin{array}{l}\text { Physical } \\
\text { examination and } \\
\text { release of vehicle }\end{array}$ \\
\hline P9 & $\begin{array}{l}\text { Physical } \\
\text { examination and } \\
\text { release of } \\
\text { vehicle }\end{array}$ & $\begin{array}{l}\text { Shipping } \\
\text { release request }\end{array}$ & $\begin{array}{l}\text { WHENEVER < importer makes shipping } \\
\text { release request > IF < request is granted > } \\
\text { THEN <Customs> IS < obliged > to perform } \\
\text { physical examination and release the vehicle } \\
\text { through GCMS }\end{array}$ & $\begin{array}{l}\text { Procurement of } \\
\text { temporary number } \\
\text { plates from DVLA }\end{array}$ \\
\hline P10 & $\begin{array}{l}\text { Procurement of } \\
\text { temporary } \\
\text { number plates } \\
\text { from DVLA }\end{array}$ & $\begin{array}{l}\text { Physical } \\
\text { examination } \\
\text { and release of } \\
\text { vehicle }\end{array}$ & $\begin{array}{l}\text { WHENEVER < Customs completes physical } \\
\text { examination and release a vehicle }>\text { IF } \\
<\text { importer fulfils all obligations }>\text { THEN } \\
\text { <DVLA }>\text { IS <obliged }>\text { provide temporary } \\
\text { number plate to importer }\end{array}$ & <vehicle cleared> \\
\hline
\end{tabular}

Stage 3: Behaviour Articulation. Based on the last stage of our framework, we perform behaviour articulation. The aim of this stage is to derive behaviours of multiagents from the case study. The result from the stages 1 and 2 are essential to behaviour articulation. Using the adapted organisation morphology technique from organisational semiotics theory, we classify multi-agent behaviours in DBEs as: substantive, communication, and control. However, there are further breakdown of these three main behaviours into sub-behaviours. Drawing from the results of stages 1 and 2 in our case study, we identify the behaviours exhibited by agents as they undertake processes. Table 4 presents behaviours articulated from our case study based on the interaction between social and digital agents.

For instance, from our case study, process P3 in which importer submits vehicle clearing application electronically for CCVR involves two agents - importer and PAARS. The importer as a social agent performs a key function of submitting vehicle clearing application form. As such, we articulate the substantive behaviour from this process. On the other hand, PAARS as a digital agent is responsible for enabling the importer to submit application (core function), checking for accuracy (control function) and communicating outcome of the process (communication function). As such, the substantive.control.communication behaviour is delineated for PAARS under process $\mathrm{P} 3$. This behaviour of PAARS in process P3 is evident in other digital agents under processes P1, P2 and P5. 
Furthermore, there are other behaviour types exhibited by multi-agents in DBEs. From our case study, under process P6 in which Customs officers as social agents evaluate declarations to determine their compliance with clearance regime is a core function. However, in performing this function, the officers are required to check if certain established rules are obeyed by importers. As such, there are elements of both substantive and control behaviours with respect to Customs compliance processes hence, the substantive.control behaviour delineation. Similarly, the digital agent GCMS under process P6 demonstrates substantive.control behaviour since it helps checks declarations for compliance and also makes sure all mandatory checks are made before allowing the process to be completed. Given that human errors are inevitable, the control behaviour of digital agents in the case study is to safeguard some of these eventualities. As illustrated in Table 4, the three main behaviour classes can have subcategories. Thus, we proposed appropriate sub-categorisation to accommodate complex behaviours.

Table 4. Behaviour articulation from vehicle clearing processes of Ghana's port DBE

\begin{tabular}{cll}
\hline $\begin{array}{c}\text { Process } \\
\text { ID }\end{array}$ & \multicolumn{1}{c}{ Processes } & \multicolumn{1}{c}{ Agents and Behaviours } \\
\hline P1 & Obtaining UCR & Importer $\rightarrow$ Substantive \\
& & e-MDA $\rightarrow$ Substantive.control.communication \\
P2 & Submitting IDF & Importer $\rightarrow$ Substantive \\
& & e-MDA $\rightarrow$ Substantive.control.communication \\
P3 & Submitting CCVR application & Customs $\rightarrow$ Substantive \\
& & PAARS $\rightarrow$ Substantive.control.communication \\
P4 & Processing CCVR application & Customs $\rightarrow$ Substantive.control \\
& & PAARS $\rightarrow$ Substantive.control \\
P5 & Declaration submission & Importer $\rightarrow$ Substantive \\
& & GCMS $\rightarrow$ Substantive.control.communication \\
P6 & Compliance \& duty determination & Customs $\rightarrow$ Substantive.control \\
& & GCMS $\rightarrow$ Substantive.control \\
P7 & Duty payment & Importer $\rightarrow$ Substantive \\
& & Bank $\rightarrow$ Substative.communication \\
P8 & Shipping release request & Importer $\rightarrow$ Communication \\
& & GICCS $\rightarrow$ Substantive.communication \\
P9 & Physical examination and release of vehicle & Customs $\rightarrow$ Substantive.control \\
& & GCMS $\rightarrow$ Substantive.control \\
& & Importer $\rightarrow$ Substantive \\
from DVLA & DVLA $\rightarrow$ Substantive \\
\hline & &
\end{tabular}




\section{Discussion and Conclusion}

This paper presented a behaviour analysis framework as its main contribution to research and practice. The framework provides a mechanism to understand multi-agent behaviours in DBEs since limited research exists on this perspective. The framework establishes three main and other sub-behaviours for multi-agents in DBEs (see Table 4). The three main behaviours are substantive, communication and control. The other sub-behaviours are substantive.communication, substantive.control, communication.substantive, communication.contro, control.substantive, and control.communication. These behaviour taxonomies can be further expanded to accommodate three sub-behaviours such as substantive.control.communication. With these behaviour taxonomies, our framework provides a novel multi-level view to articulate agent behaviour in complex DBE interactions. As a result, DBE functions can be better delegated between agents for optimal operation since our framework reveals which behaviours are mostly suitable for social and digital agents. As agent behaviour is fundamental to DBE success, it is vital to have a holistic understanding especially for systems analysts, developers, and managers who confront the complexities of supporting multi-agent and developing new service innovations. Our study extends DBE research by presenting a framework that specifies taxonomies of multi-agent behaviours. With this framework, systems analysts and developers can design effective systems for DBEs to achieve their goals by accurately classifying multi-agent behaviours and appropriately apportioning activities.

Aside the multi-view of behaviour articulation, our framework provides a technique to systematically delineate DBE agents to correctly define the scope of investigation. We consider this a vital contribution to DBE research since it has been difficult to articulate agents for further analysis [4]. Given that DBEs comprise complex interdependencies between multi-agents, the extant research mainly resorted to perceptual approaches in articulating agents. For instance, due to unavailability of a systematic approach to articulate DBE agents, in developing a conceptual foundation for smart tourism ecosystems, Gretzel et al. [3] used perceptual means to identify agents.

In addition, this study shows that digital agents mostly carry out communication and control behaviours while social agents perform substantive behaviours. This insight confirms the position in the IS literature that giving responsibility to digital agents to enforce rules ensures better results. In addition, using digital agents to enforce rules offer benefits such as elimination of favouritism, efficient processes, shorter processing times, reduced errors, corruption minimisation and so on. With this knowledge, it is easier for system analysts and developers to decide which functions to apportion to digital agents in DBEs.

Notwithstanding the capabilities of digital agents, our study buttresses the point that not all behaviours can be undertaken by digital agents [13] specifically, core processes requiring unplanned discretionary decisions. As such, some substantive behaviours must still be undertaken by social agents to augment limitations of digital agents. While there are arguments that digital agents can learn through machine learning techniques, our study demonstrates that heterogeneous environments like DBEs need both social and digital agents to operate effectively. We illustrated our framework in a single DBE, 
hence we call for validation of our framework in other ecosystems such as mobile, ecommerce, and software DBEs.

\section{References}

1. Basheer, G.S. et al.: Certainty, trust and evidence: Towards an integrative model of confidence in multi-agent systems. Comput. Human Behav. 45, 307315 (2015).

2. Evertsz, R. et al.: A framework for modelling tactical decision-making in autonomous systems. J. Syst. Softw. 110, 222-238 (2015).

3. Gretzel, U. et al.: Conceptual foundations for understanding smart tourism ecosystems. Comput. Human Behav. 50, 558-563 (2015).

4. Iansiti, M., Levien, R.: Strategy as Ecology. Harv. Bus. Rev. 82, 3, 1-14 (2004).

5. Jiao, W., Sun, Y.: Self-adaptation of Multi-agent Systems in Dynamic Environments Based on Experience Exchanges. J. Syst. Softw. 122, C, 165179 (2016).

6. Li, W. et al.: A Semiotic Multi-Agent Modeling Approach for Clinical Pathway Management. J. Comput. 5, 2, 266-273 (2010).

7. Liu, K. et al.: Modelling complex systems for project planning: a semiotics motivated method. Int. J. Gen. Syst. 35, 3, 313-327 (2006).

8. Liu, K.: Requirements Reengineering from Legacy Information Systems Using Semiotic Techniques. Syst. Signs Actions. 1, 1, 38-61 (2005).

9. Liu, K.: Semiotics in Information Systems Engineering. Cambridge University Press (2000).

10. Mingers, J., Willcocks, L.: An integrative semiotic framework for information systems: The social, personal and material worlds. Inf. Organ. 24, 1, 48-70 (2014).

11. Moore, J.F.: Predators and prey: a new ecology of competition. Havard Bus. Rev. 71, 3, 75-83 (1993).

12. Nachira, F. et al.: A network of digital business ecosystems for Europe: roots,processes and perspectives. In: Digital Business Ecosystem. European Commission Information Society and Media (2007).

13. Senyo, P.K. et al.: Evolution of norms in the emergence of digital business ecosystems. In: Baranauskas, M. et al. (eds.) Socially Aware Organisations and Technologies. Impact and Challenges. pp. 79-84 Springer, Cham (2016).

14. Wooldridge, M.: Introduction to Multiagent Systems. Wiley \& Sons (2002). 